Section 1526

\title{
Case Study Based Laboratories for an Undergraduate Human Factors Engineering Curriculum
}

\author{
Ann M. Bisantz, Victor L. Paquet \\ Department of Industrial Engineering \\ University at Buffalo, State University of New York \\ Amherst, NY 14020 \\ bisantz@eng.buffalo.edu
}

\begin{abstract}
This paper describes the ongoing implementation and evaluation of a set of design-oriented laboratory exercises for two undergraduate Human Factors and Ergonomics (HFE) courses, which draw from a case study model. The case material, based on the automotive manufacturing industry, includes the description of the overall manufacturing system, seven multi-period laboratories across the two courses, and computer modules intended to support the design and analysis activities in the laboratories. Over the duration of the project, the courses are being taught using the modified laboratories, and evaluations, including student surveys, grade comparisons, and comparison of test question answers, are being conducted to compare student performance before and after the implementation of the proposed laboratories. Results from completed evaluations are discussed.
\end{abstract}

\section{Background}

Ergonomics (IE 323) and Methods and Measurement (IE 424) are required courses in which undergraduate Industrial Engineering (IE) students learn how to improve human performance through the design of complex systems. IE 323 concentrates on aspects of human information processing, problem solving and decision making, sensory systems processing, communication and human error. IE 424 covers the physical requirements of work, emphasizing the design of work systems that promote worker productivity, health and wellbeing. Appropriate experimental methods are also covered. Both courses have laboratories which require students to apply concepts learned in class. Previously, these sessions consisted of independent activities that had not been designed to fully address open ended engineering design problems. The new case study consists of seven interrelated laboratories conducted over two semesters, to be performed by groups of 3-5 students.

The proposed project integrates laboratory experiences within and across two HFE courses using a manufacturing case study. The laboratories are based on a automotive manufacturing case, developed in cooperation with, and based on, information provided by HFE and safety personnel of a large automotive manufacturing facility (a thermal systems manufacturing plant). The case 
consists at the general level of a description of a automotive manufacturing company, including its configuration, employees, customer base, resources, departments, and processes.

Supplementary details about systems, task requirements, workstations, and processes are provided throughout the courses, to provide context for the proposed laboratories.

Case studies have been used to enhance learning across a range of curricula, including medicine, law, business, science, and engineering. Cases have been suggested as a means to enhance learning, by requiring analytic and critical thinking skills, illustrating the real life complexities of course content, and providing a realistic setting to apply course material ${ }^{1-3}$. In engineering, cases have been suggested as a basis for laboratory exercises as a means to incorporate design content into courses ${ }^{4,5}$ and as an illustration of the multi-disciplinary nature of engineering projects ${ }^{1}$.

Cases can be taught differently, including through a discussion format, as debates or trials, or as a scientific research project ${ }^{3}$. The latter includes providing students with background information and a problem to be solved, and having students make hypotheses, develop experiments, collect data, and evaluate results with respect to the hypotheses. Here, the proposed laboratories will implement case studies based on real industrial problems in the areas of workstation and work process design. The case will be similar to the research project format but be adapted to a design, rather than hypothesis testing focus - students will be given a design problem and then apply experimental and analytical methods to find solutions.

The potential benefits of case studies are consistent with an educational approach which emphasizes the need to support a variety of learning styles. For instance, some students are better at processing information using an active, hands-on style rather than a passive, reflective style, some prefer a deductive standpoint (e.g. reasoning from theory to applied facts) and others an inductive standpoint (from data to theories ${ }^{6}$ ). Using cases can encourage students to use less familiar styles, by having them address questions such as why the material is important (e.g., by emphasizing the application of material and methods to design), what the content is, how the methods can be applied (e.g., through the laboratories) and finally, how the material can be applied to novel circumstances (e.g., by providing design problems). Because the proposed laboratory changes address the needs of different styles of learners, the changes may also help improve student retention.

\section{Case Development}

To develop the case material, interviews and tours with HFE and safety professionals from a local automotive manufacturing facility were used to provide the context of the case study. Detailed information was collected about the companies including the organizational structure, production requirements, industrial processes, job requirements and existing technologies. This information was used to construct realistic and challenging HFE problems that involved the design of displays and controls, visual inspection tasks, computer system requirements, job task requirements, workstations and the organization of work.

\section{Laboratory Descriptions}

The goals of the redesigned laboratories are: $\underline{1}$. To emphasize the application of HFE course material to real-world problems. 2. To ground the study of HFE within the context of industrial 
engineering, using a manufacturing case study to motivate the laboratories. $\underline{\text { 3. To provide }}$ students with laboratories in which they can obtain skills in the identification and investigation of research or design questions. $\underline{4}$. To allow students to use current technologies and techniques in interface prototyping and industrial ergonomics work analysis. $\underline{\mathbf{5}}$. To motivate students of different learning styles to master course material.

The laboratory descriptions are provided below. Note that the revised IE 323 laboratories were used for the first time in Spring, 2001, and the revised IE 424 laboratories were used for the first time in Fall, 2000.

IE 323 Laboratory 1: Design of a Control Panel: Students design industrial process control panels for the manufacturing system, in order to investigate and apply principles in the design of displays and controls, including display-control compatibility, functional groupings, good mappings, and accommodation of population stereotypes ${ }^{7,8}$. Methodologically, students design a simple experiment and questionnaire to test their designs, using subjective and objective measures. Students first design several potential control panels, trading off various design principles to meet space and functionality constraints. They design and implement a questionnaire to collect data about their designs, including responses to potentially ambiguous control-display configurations that occur in their designs. Student then analyze the questionnaire results, and apply that information to a final design, which are implemented using preconstructed control-display building blocks implemented in Visual Basic. They conduct tests, consisting of a set of interaction tasks using the control panel, collecting data about errors made, questions asked, and users' subjective ratings of the design.

IE 323 Laboratory 2: Design of a Visual Inspection Workstation: Students design a Visual Inspection Workstation for a manufacturing system by applying two models of human performance to the design of an computerized visual inspection workstation. Signal Detection Theory (SDT) models how an observer distinguishes two states (in this case, good product/faulty product) and includes relevant performance parameters. The Hick-Hyman Law is used to predict the time it takes to respond to one of several possible stimuli based on the number of stimuli, and their probabilities of occurrence. Students first read a description of the visual inspection process in the plant, including a preliminary design for a computerized real-time inspection station which incorporates photos of products after assembly, and examples of common faults. Students then apply the two models in considering how different design parameters (e.g., the time given to inspect each assembly, the size of the pictures, the interface layouts) impact task performance, and how to adjust parameters to optimize performance. Students then configure a simulated workstation in order to collect data to test their predictions. They are provided with preconstructed, configurable display and control modules for the Inspection Station, implemented in Visual Basic, to facilitate this laboratory. Using the workstation, students perform experiments to test their predictions.

IE 323 Laboratory 3: Design of a Production Support System: Students design a computer system to facilitate inventory control and production scheduling by applying principles of human-computer interaction and methods of design for usability, including gathering design requirements from potential users, performing task analyses, modeling performance, and iteratively testing and refining their design. Students are first given a description of production 
planning needs in an automotive manufacturing facility, including inventory control, scheduling, and material ordering needs. They then construct task analyses based on these requirements and production requirements given in the case. From these analyses, students design an initial prototype for the various screens in their interface (e.g., a set of storyboards). Students then obtain initial feedback from potential "users," and implement a limited function prototype using PowerPoint animation. Students then collect data in a usability test about how users actually perform these tasks, and errors or difficulties that arise. Finally, students propos design changes based on these results.

IE 424 Laboratory 1: Preliminary Design of the Manufacturing Process: Students design and evaluate the basic components of the manufacturing system, including manual materials handling $(\mathrm{MMH})$, assembly and packaging, as well as the automated warehouse system, inspection and the production support systems developed in IE 323 by practicing workplace evaluation, function description and analysis, and task analysis ${ }^{9,10}$. Students first define the materials, labor (jobs), and equipment needed to manufacture parts of a specific automotive manufacturing process. Groups of four to five students perform hierarchical task analyses (HTA) to develop a list of the cognitive, psychological and physical requirements for manufacturing jobs within the system.

IE 424 Laboratory 2: Design of Manufacturing Workstations: Students design the manufacturing system workstations using anthropometric dimensions (body sizes and weights), population databases, and anthropometric reach and clearance envelopes. Students first use anthropometric equipment to measure other students' weight, stature, standing eye height, seated eye height, thumb-tip reach, and seated elbow height. The class data are compared to general working population data and the information is used in the design of the workstations. Groups use human modeling software packages (MannequinONSITE ${ }^{\mathrm{TM}}$ and MannequinPRO ${ }^{\mathrm{TM}}$ ) to evaluate the fit between physical characteristics of people and one workstation. This requires students to determine zones of convenience for reaches, clearance envelopes, and safe distances from danger points ${ }^{11}$.

IE 424 Laboratory 3: Design of Physical Job Requirements: Students design the physical requirements of jobs by evaluating job scenarios using biomechanical, physiological and psychophysical methods of work measurement. Student groups first perform a detailed ergonomic job analysis of each job to identify excessive physical job requirements ${ }^{12}$. Each group then develops hypotheses about how workplace characteristics affect the physical requirements of one job, develops an experiment to test the hypotheses, collects and analyzes data, and interprets the results. Data collection involves quantifying the physical job requirements with video, observational checklists, interviews, biomechanical analysis software, and/or physiological monitoring equipment while students simulate job tasks.

IE 424 Laboratory 4: Design of the Work Organization: Students design the work organization structure of the manufacturing system by considering how organizational issues affect job demands, control over work activities, job content and system adaptability and productivity. Student groups first role-play as employees (management and operators) and evaluators of the system. Production is simulated in the laboratory under different organizational conditions that include the use of incentive-based production policies, job rotation and job enlargement. Performance of the manufacturing system is assessed with the measurement of employee 
productivity, psychological stress and potential for skill acquisition. During the final laboratory session, student groups make a formal presentations of a final integrated task and system design to the class and instructor.

\section{Evaluation Methods}

Several approaches have been used to assess the effectiveness of individual courses, including comparing overall outcomes through course grades, comparing grades on individual quizzes or assignments designed to test the influence of a new course components ${ }^{13,14}$, and regular course evaluations ${ }^{15}$. Administering surveys is also common ${ }^{16}$. IE 323 and 424 were taught before the proposed changes were implemented in Fall 2000, allowing a comparison between sections using the traditional laboratories to those using the revised laboratories. The formal evaluation uses four techniques:

1. Student Surveys: Anonymous surveys were administered twice in each course, for comparison before and after the laboratory changes. Survey questions are shown in Table 1. We expected, due to the changes, that the laboratories would be seen as more relevant and applicable to students' future careers, and that this effect would transfer to perceptions of course material and interest in the field.

2. Test Questions: A test question was administered as part of the final examination for IE 323 and IE 424, both before and after the changes, in the form of essay questions asking students to apply course content and methods to an industrial design problem. Answers were graded as part of the exams, and were saved for later analyses. Content and ideas expressed in the essay answers will be identified and categorized, and the results were compared across years to assess the effects of the changes. We expect that students would apply more and more detailed course concepts, and better methodologies, to answer these design questions, after the changes. A random sample of questions from 10 students were drawn from each offering of IE 323 and 424, to be rated for course content and ideas by four other human factors educators, to provide independent verification of the reliability of the PI's ratings.

3. Outcome measures: Grades (from tests, laboratories, and overall), and responses to standard course evaluations were compared to identify general between-group differences.

4. Industry Feedback: Qualitative feedback in the form of written comments will be elicited from the manufacturing personnel who provided the case material.

The reliance on student-produced measures, such as survey responses and course evaluations, and objective measures such as the number and type of content and methodological concepts expressed in student work, along with the independent rating of randomly sampled test questions, helped to insure that the results are impartial. 
Table 1. Survey Questions. Responses are on a 7 point scale from Strongly Disagree (1) to Strongly Agree (7).

1. I think the material covered in course lectures is useful in designing jobs, workplaces, or systems.

2. I think the material learned in the laboratories is useful in designing jobs, workplaces, or systems.

3. I think Human Factors Engineering is an interesting topic of study.

4. I would like to take technical electives or graduate courses in some area of Human Factors.

5. I learned a lot about human factors by doing and writing up the labs.

6 . I feel that the time I spend doing the labs is worth it, in terms of the amount I am learn through them.

7. I am learning design and work analysis methods in class lectures which will be useful in designing jobs, workplaces, or systems.

8. I am learning design and work analysis methods in the laboratories which will be useful in designing jobs, workplaces, or systems.

9. I think I will be able to apply material and methods learned in class to real world human factors problems.

10. I think I will be able to apply material and methods learned through the laboratories to real world human factors problems.

\section{Results}

To date, a subset of the evaluation data and analyses have been completed, corresponding to data available from the course offerings that have taken place. Data have been collected from one offering of IE 323, and two offerings of IE 424. Comparative analyses of course grades, test question grades, and answers to survey questions from IE 424 have been completed and are described below. Content analyses of test questions, comparison of formal course evaluation data, and analyses by other human factors professionals are ongoing. Data from IE 323 will be analyzed after the post-implementation offering of that course in the Spring of 2001.

Figures 1 and 2 show results of the class survey and midterm and final exam scores and grades for IE 424, before and after the implementation of the new laboratories. Surveys were given at the end of each course offering. T-test results showed significant increases in ratings of survey questions (a positive shift) for questions $1\left(\mathrm{t}_{34}=-2.00 ; \mathrm{p}=.053\right), 2\left(\mathrm{t}_{34}=-2.08 ; \mathrm{p}=.045\right)$, and 10 $\left(\mathrm{t}_{34}-1.86 ; \mathrm{p}=.072\right)$. Thus, students responded that they thought the material covered in class and the laboratories was more useful for design, and that they would be more able to apply material and methods from the laboratories to real world problems, after the revised laboratories were implemented. There were non-significant increases in responses to questions 3, 4, 7, 8 and 9. There was not a significant change in students' perceptions of laboratory workload after the changes, however (questions 5 and 6).

T-test results for exam and course grades indicate that there was a significant decline in the midterm exam question score $\left(\mathrm{t}_{45}=1.8 ; \mathrm{p}=.09\right)$, but a significant improvement in the final exam grade $\left(\mathrm{t}_{46}=-3.5 ; \mathrm{p}=.001\right)$, which required students to provide a solution to an open-ended 
workstation design problem, in a take-home exam. There was no significant difference in final course grades.

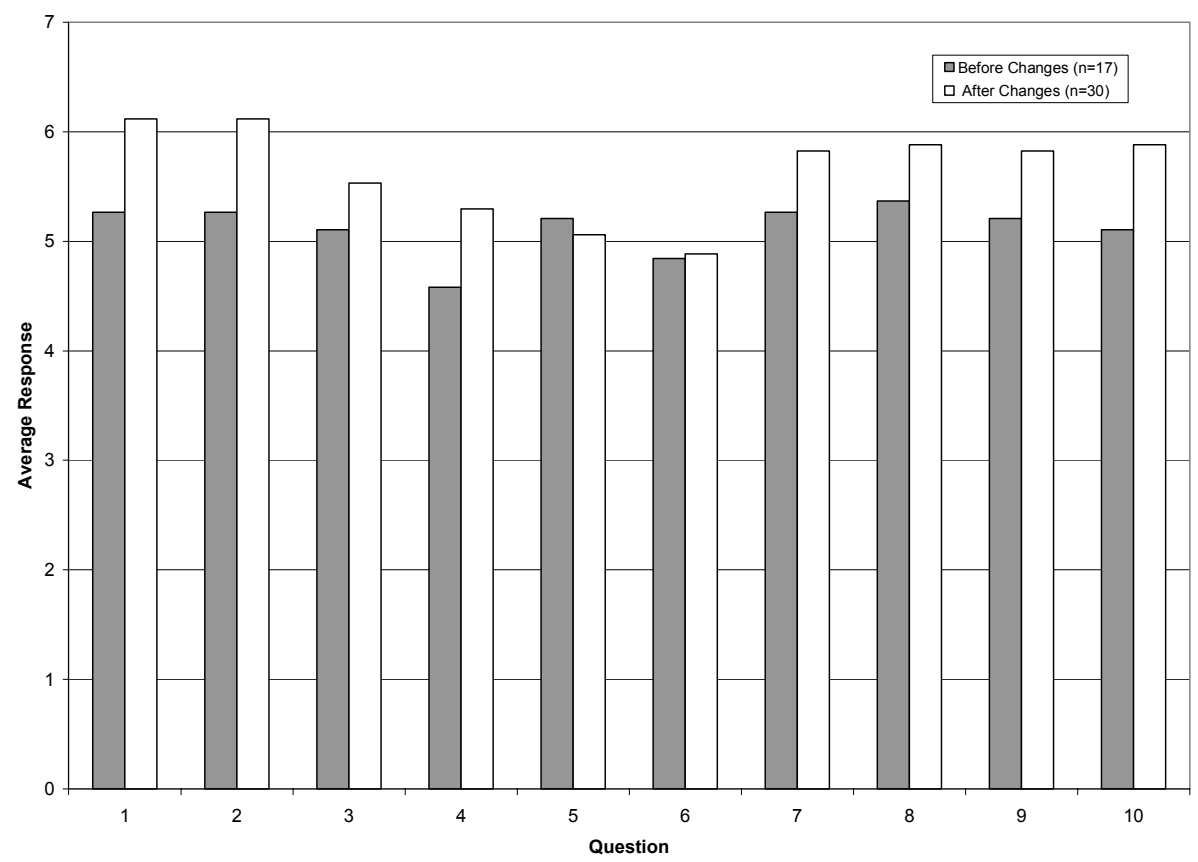

Figure 1. Mean Responses to Survey Questions for IE 424, before and after the new laboratories were implemented.

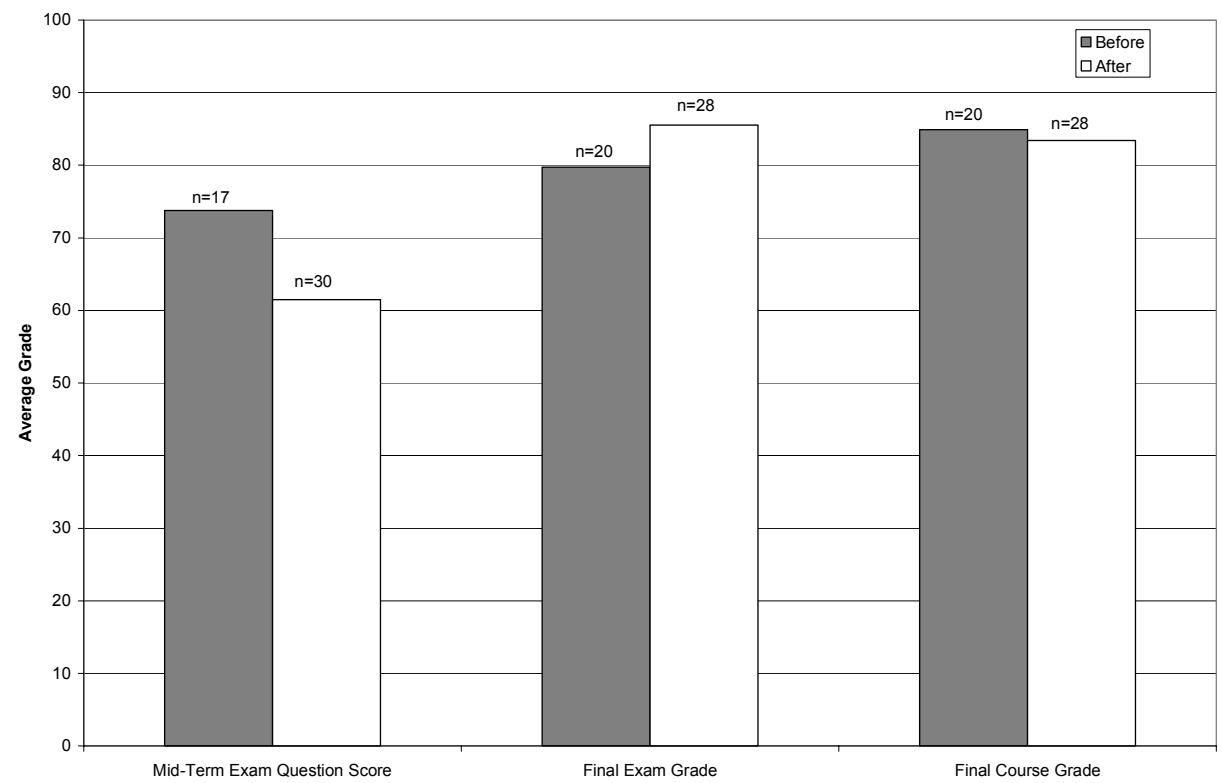

Figure 2. Average Student Performance, before and after the new laboratories were implemented. 


\section{Discussion}

Overall, the implementation of the revised laboratories in IE 424 had a positive affect on student perceptions of the utility and applicability of material and methods covered in both the course and laboratories, and a neutral effect on student interest in Human Factors, and their perceptions of laboratory workload. Thus, the implementation of the revised laboratories may have had a positive impact on students' perceptions of both the laboratory and course material, without a significantly negative impact on their perception of laboratory workload.

One possible factor influencing these results is the timing of the new laboratory implementation. Due to the starting date of the project, the new laboratories were implemented in IE 424 in Fall, 2000 and new laboratories were implemented in IE 323 in Spring, 2001. The normal course sequence is for students to take IE 323 in the spring of their junior year, and IE 424 in the fall of their senior year. Therefore, students who experienced the revised IE 424 laboratories had seen the original IE 323 laboratories the previous spring. Since their expectations regarding the laboratory experiences were based on the original IE 323 laboratories, which required students to do less open-ended work on their own, students may have felt less comfortable with the new format. Thus, students, while recognizing the applicability of the new laboratories, may not have believed they were learning any more much relative to the work involved (survey questions 5 and 6).

Students' performance on a design related mid-term question, and in the course overall tended to be lower in the second course offering than the first; however, this result may be due to general differences in abilities across the two years. The grade on the final exam, which required students to answer an in depth, open-ended take home design question, did improve for students who experienced the revised laboratories. This is an expected result, since the new laboratories were much more open-ended and design oriented than the previous laboratory exercises.

The introduction of the new laboratory experiences did have its problems. For example, the new IE 424 laboratories required students to be fairly proficient in the use of CAD in order to design and evaluate computerized models of the manufacturing workstations. Several hours of CAD tutorials were given to students in the beginning of the semester, but this tutorial was found not to contain sufficient depth or breadth. Fortunately, many of the students in the class had prior CAD experience, and students were able to work together to complete the workstation designs. Next fall improvements will be made to the tutorial and efforts will be made to ensure that each team has at least one student who has a high proficiency in CAD.

Possible extensions to the project include an expansion of the case study into other Industrial Engineering courses. Beyond the two courses discussed in the proposal, the case study and laboratories could be extended in the future for use in other core IE courses including Production Systems, Facilities Design, Quality Assurance, and Engineering Economy.

\section{Conclusions}

A set of case-study based, design oriented laboratory exercises was developed for a two course sequence in Human Factors Engineering. Results comparing student opinions and performance 
before and after the implementation of the laboratories in one of the two courses indicated that students' perceptions of the utility and applicability of course material as well as laboratory material improved after the revised laboratories were implemented, without a significantly negative impact on their perception of laboratory workload. Also, though course performance overall declined, performance on an open-ended, design oriented final exam improved. Thus, the results gathered to date indicate some positive impact of the new laboratories in terms of students' abilities to apply Human Factors knowledge to more real-world, design oriented problems.

\section{Acknowledgement}

This work was supported by an NSF Course, Curriculum, and Laboratory Improvement Grant \# DUE-9980971, and a University at Buffalo Ed-Tech Grant.

\section{Bibliography}

1. Chinowsky, P.S. and J. Robinson, Enhancing civil engineering education through case studies. Journal of Engineering Education, 1997. 86(1): p. 45 - 50.

2. Cliff, W.H. and A.W. Wright, Directed case study method for teaching human anatomy and physiology. Advances in Physiology Education, 1996. 15(1): p. 19 - 28.

3. Herreid, C.F., Case studies in science: A novel method of science education. Journal of College Science Teaching, 1994(February): p. 221 - 229.

4. Kardos, G. and C.O. Smith, Engineering cases as tools for teaching design. Mechanical Engineering, 1983: p. $68-71$.

5. Smith, C.O. and G. Kardos, Need design content for accreditation? Try engineering cases. Engineering Education, 1987(January): p. 228 - 230.

6. $\quad$ Felder, R.M. and L.K. Silverman, Learning styles and teaching styles in engineering education. Engineering Education, 1988. 78: p. 674 - 681.

7. Wickens, C., Engineering Psychology and Human Performance. 1992, Glenview, IL: Scott, Foreman, and Co.

8. $\quad$ Norman, D.A., The Psychology of Everyday Things. 1988, New York: Basic Books.

9. $\quad$ Drury, C., Task analysis methods in industry. Applied Ergonomics, 1983. 14(1): p. 19 - 28.

10. Luczak, H., Task analysis, in Handbook of Human Factors and Ergonomics, G. Salvendy, Editor. 1997, Wiley: New York. p. 340 - 416.

11. Kroemer, K., H. Kroemer, and J. Kroemer-Elbert, in Ergonomics: How to design for ease and efficiency., Fabrycky and Mize, Editors. 1994, Prentice Hall: Englewood Cliffs, NJ.

12. Keyserling, M., T. Armstrong, and L. Punnet, Ergonomic job analysis: A structured approach for identifying risk factors associates with overexertion injuries and disorders. Applied occupational and Environmental Hygiene, 1991. 6(5): p. 352 - 363.

13. Flori, R.E., M.A. Koen, and D.B. Oglesby, Basic engineering software for teaching "best" dynamics. Journal of Engineering Education, 1996. 85(1): p. 61 - 68.

14. Wallace, D.R. and P. Mutooni, A comparative evaluation of world wide web-based and classroom teaching. Journal of Engineering Education, 1997. 86(3): p. 211 - 220.

15. Waitz, I.A. and E.C. Barrett, Integrated teaching of experimental and communication skills to undergraduate aerospace engineering students. Journal of Engineering Education, 1997. 86(3): p. 255 262.

16. Demetry, C. and J.E. Groccia, A comparative assessment of students' experiences in two instruction formats of an introductory materials science course. Journal of Engineering Education, 1997. 86(3): p. 203 - 210.

Proceedings of the 2001 American Society for Engineering Education Annual Conference \& Exposition Copyright (C) 2001, American Society for Engineering Education 


\section{ANN M. BISANTZ}

Ann M. Bisantz is an Assistant Professor of Industrial Engineering at the University at Buffalo. Dr. Bisantz's research interests include complex decision-making, human-machine systems, and human-computer interaction. In addition to teaching undergraduate human factors courses, she offers graduate courses in Research Methods, Cognitive Engineering, and Human Computer Interaction.

\section{VICTOR L. PAQUET}

Victor L. Paquet is an Assistant Professor of Industrial Engineering at the University at Buffalo. Dr. Paquet's research interests include the evaluation of ergonomic stressors in occupational settings, outcome assessment for ergonomic interventions, and anthropometry. He teaches undergraduate and graduate courses in occupational ergonomics and safety. 